\title{
Fluorescence Lifetime Imaging Microscopy
}

National Cancer Institute

\section{Source}

National Cancer Institute. Fluorescence Lifetime Imaging Microscopy. NCI Thesaurus.

Code C154786.

An imaging technique that produces spatially resolved images based on the differences in the excited state decay rates of fluorescent compounds in a sample. 